\title{
Diablotexto
}

\section{Las narrativas digitales en Educación Infantil: una experiencia de investigación e innovación con booktrailer, cuentos interactivos digitales y Realidad Aumentada}

Digital Narratives in the Preschool Classroom: an Experience of Research and Innovation with Booktrailer, Interactive Digital Stories and Augmented Reality

\section{ALICIA VARA LÓPEZ \\ UNIVERSIDAD DE CÓRDOBA}

\begin{abstract}
Resumen: Con el desarrollo de la tecnología de la comunicación, la narrativa infantil ha ensanchado sus horizontes estéticos y expresivos. Las narrativas digitales emergen como una herramienta pedagógica útil para el profesorado porque captan la atención del alumnado y encajan con sus intereses. Esta experiencia de investigación e innovación, desarrollada en la Universidad de Córdoba, se centra en el estudio de recursos digitales para la educación literaria. Hemos seleccionado tres productos que ofrecen múltiples posibilidades para el aula de Educación Infantil: booktrailer, cuento digital interactivo y aplicaciones de Realidad Aumentada. El presente trabajo aborda sus múltiples posibilidades de implementación en el campo educativo para trabajar temáticas esenciales como la gestión de las emociones, la diversidad familiar o el respeto por los animales.
\end{abstract}

Palabras clave: educación, literatura infantil, narrativas digitales, booktrailer, cuento interactivo digital, Realidad Aumentada

Abstract: With the development of communication technology, children's stories expand their aesthetic and expressive horizons. Digital narratives become a useful pedagogical tool for teachers because they catch student's attention and fit their interests. This experience of research and innovation, developed at the University of Córdoba, focuses on the study of digital resources for reading education. We select three products that offer us many possibilities in Preschool Classroom: booktrailer, interactive digital story and Augmented Reality devices. Our work considers their many possibilities of implementation in the educational field to work essential subjects such as management of emotions, family diversity or respect for animals.

Key words: Education, Children's Literature, Digital Narratives, Booktrailer, Interactive Digital Story, Augmented Reality 


\section{Introducción}

La didáctica de la lengua y la literatura se encuentra en la actualidad en un proceso de renovación, de acuerdo con la necesidad de adaptarse a las características e intereses de las nuevas generaciones lectoras (TaberneroSala, 2015; Rovira-Collado, 2015). En Educación Infantil, más que en cualquier otra etapa, es necesario poner en contacto al alumnado con narrativas próximas a sus intereses, que ayuden a comprender su mundo. Frente a una educación tradicional en la que el papel se erigía como único soporte posible para la lectura en las aulas y fuera de ellas, surgen ahora propuestas multimediales y multimodales en las que el texto literario comparte protagonismo con la imagen y el sonido (Unsworth, 2006; Lloret y Canet, 2008; Landow, 2009; Cassani, 2011, 2012; Ibarra-Rius y Ballester-Roca, 2016). En el ámbito de la literatura infantil novedosos productos digitales como los booktrailers, los cuentos interactivos o las aplicaciones con Realidad Aumentada, conviven con los tradicionales libros en soporte papel (Navarro, 2005: 268).

Los medios y tecnologías de la comunicación son un instrumento idóneo para una escuela que en la actualidad se halla en proceso de adaptación al nuevo panorama comunicativo vigente: se puede hablar ya de "escuela 2.0". Las aulas del siglo XXI avanzan hacia una construcción del conocimiento interactiva y compartida (Tabernero-Sala, 2013: 219). En este contexto, IbarraRius y Ballester-Roca (2016) señalan las narrativas digitales como herramientas metodológicas idóneas para abordar la didáctica de la lengua y la literatura, en tanto que sirven para acercar al alumnado a historias y personajes de ficción, en la línea de la literatura tradicional, y además dotan al aula de innumerables posibilidades en cuanto a tipologías y soportes de lectura y escritura.

Con la generalización de los formatos audiovisuales, el lector o lectora pasa a ser protagonista de su propio aprendizaje, al tiempo que desarrolla de manera global y simultánea competencias como la lingüística, la comunicativa, la digital o mediática, la lectora y la literaria (Sánchez-Claros, 2016; RoviraCollado, 2017). No se trata de alejarse de la palabra y su potencial comunicativo, sino de combinarla con experiencias visuales y participativas, de 
acuerdo con la concepción interactiva de la lectura que propone Mendoza Fillola $(2003,2007)$.

La experiencia de investigación e innovación educativa que aquí se expone parte del propósito de formar a las futuras maestras y los futuros maestros de Educación Infantil en el sentido crítico y las habilidades didácticas necesarias para hacer un uso responsable y adecuado de las narrativas digitales emergentes. El objetivo principal es poner en contacto a estudiantes del Grado en Educación Infantil, por la vía de la investigación, con nuevos materiales narrativos a los que se puede acceder a través de internet. De esta manera, se promoverá una reflexión acerca de su potencial educativo".

El período de Educación Infantil requiere un tipo de literatura adaptada a las necesidades particulares de la etapa, puesto que a menudo el alumnado de estas edades cuenta con limitadas nociones de lectoescritura. En este sentido, es especialmente imprescindible la mediación adulta para el acceso a los textos, de forma que la cooperación y la interacción, a menudo pautadas, se convierten en los principales pilares del proceso lector (Ibarra-Rius y BallesterRoca, 2016). De acuerdo con ello, Mendoza Fillola $(2003,2007)$ establece que la figura mediadora debe tener en cuenta los intereses y las limitaciones (lingüísticas, discursivas, temáticas, etc.) que presente el lector o la lectora a la hora de seleccionar textos acordes con sus capacidades y expectativas.

Para lograr la necesaria formación de los maestros y las maestras a este respecto, se está llevando a cabo un conjunto de innovadoras propuestas destinadas a incorporar las narrativas digitales a las aulas de las facultades de Educación ${ }^{2}$. No obstante, todavía queda mucho camino por recorrer para explorar todas las posibilidades didácticas y educativas de los materiales literarios emergentes. En las siguientes páginas se realizará una aproximación a los tres materiales digitales que se tratarán en nuestra experiencia de investigación en el aula: el booktrailer, los cuentos interactivos digitales y las aplicaciones de Realidad Aumentada.

\footnotetext{
1 Internet ofrece infinidad de posibilidades, si bien es imprescindible establecer unos criterios de selección, así como el diseño y planificación de estrategias concretas para incorporarlas en las dinámicas del aula.

2 Sirvan como ejemplo las experiencias basadas en la creación de booktrailers para Educación Infantil o Educación Primaria (Ibarra-Rius y Ballester-Roca (2016); Rovira-Collado (2017)).
} 


\section{El booktrailer}

En terminología de Genette (1987), el booktrailer puede considerarse un paratexto, pues se trata de un elemento que ayuda a introducirse en la lectura con la aportación de ciertas instrucciones acerca del contenido o el género. Además, se identifica con lo que Genette nombra como epitextos, en tanto que no aparece anexado al texto en un mismo volumen sino que circula de manera libre, pública e independiente. Según Gray (2010) y Tabernero-Sala (2013), el booktrailer surge con el propósito de promocionar un libro por medio del formato de vídeo. Para ello, utiliza técnicas cinematográficas y se difunde en las redes sociales. Lluch, Tabernero-Sala y Calvo (2015: 801) destacan el uso de estrategias del lenguaje publicitario e identifican una serie de elementos que suelen estar presentes en los booktrailers para facilitar la difusión del libro: título, autoría, editorial, personajes y elementos espacio-temporales ${ }^{3}$.

En la actualidad existen booktrailers para todo tipo de literatura pero, debido a su gran valor estético y al tema que nos ocupa, interesan para esta investigación aquellos que surgen para la promoción de la literatura infantil.

Desde un punto de vista cognitivo, el contacto con el booktrailer por parte del alumnado de Educación Infantil formaría parte de lo que Mendoza Fillola (2007) denomina "anticipación intuitiva"4. Esta actividad se inicia con la toma de contacto del lector o la lectora con el título o algún otro paratexto o epitexto, que le permite formular hipótesis sobre el texto o establecer un horizonte de expectativas. En el aula de Educación Infantil, debido a las particularidades del alumnado, el booktrailer puede actuar como foco de

\footnotetext{
${ }^{3}$ Asimismo, Tabernero-Sala $(2013,2015)$ distingue tres grandes categorías de booktrailers: la primera, de mayor sencillez técnica y muy cercana al formato del libro, consiste en una presentación en Issuu que incorpora la selección de páginas o dobles páginas del libro que resumen los aspectos más relevantes. La segunda emplea la técnica cinematográfica en la plasmación de una historia breve por medio de la música, la palabra (oral y escrita) y a veces el movimiento. Por último, la tercera categoría está constituida por cortometrajes de animación, muy alejados del formato libro.

${ }^{4}$ Dentro de la amplia fase de la precomprensión, "la anticipación es la actividad marco, inicial y provisional, desde la que el lector pone en marcha su intuición sobre las posibilidades temáticas, estilísticas, de intencionalidad, de orientación, etc., que puede presentar un determinado texto" (Mendoza Fillola, 2007: 76).
} 
atención en dinámicas previas a la propia lectura o servir como vía para suscitar interés sobre la historia o los personajes ${ }^{5}$.

\section{El cuento interactivo digital}

El uso generalizado de dispositivos móviles como las tabletas, los ordenadores portátiles o los smartphones ha promovido el desarrollo de libros ilustrados en formato digital, muchos de ellos diseñados para aplicaciones interactivas que tienen la ventaja de llevar la actividad lectora a diversos espacios y contextos ${ }^{6}$. El concepto de libro interactivo se remonta a los denominados "libros pop-up", caracterizados por la presencia de figuras tridimensionales desplegables en papel, que juegan con el efecto sorpresa y con la necesidad de que el lector o la lectora realice movimientos para descubrir nuevos volúmenes, imágenes inesperadas o actividades (Navarro, 2015) ${ }^{7}$. El objetivo es convertir el libro en un objeto lúdico, atractivo y manipulable, capaz de ofrecer distintos niveles e itinerarios de lectura que inciten a la participación.

Con la llegada de la era digital, los libros interactivos evolucionan hacia los denominados libros interactivos digitales, en los que confluyen ilustraciones similares a las que aparecen en el formato papel con elementos multimedia. En esta línea de la concepción de la lectura como un proceso lúdico y activo, aparecen en los últimos años nuevos recursos que van diferenciando cada vez más el libro interactivo digital de su homólogo en papel. La principal directriz es apostar por experiencias multisensoriales e interactivas, que capten la atención y reclamen la participación en la historia. Navarro (2015: 264) destaca en este sentido la música de fondo, los efectos de sonido, las cuñas de audio o el vídeo digital interactivo como los principales elementos multimedia. De acuerdo con su adecuación a Educación Infantil, la autora señala la habitual integración en el cuento interactivo digital de la lectura en voz alta del texto, amenizada con

\footnotetext{
${ }^{5}$ Se podrán plantear a partir de su visualización preguntas como "¿Qué crees que va a pasar después?” o “¿Cuál de los cuentos te gustaría leer?”.

${ }^{6}$ La web de referencia Generación Apps ofrece cuentos interactivos que aprovechan las posibilidades de smartphones y tabletas para proporcionar entretenimiento y contenidos educativos adaptados a distintas edades: http://generacionapps.com/ [fecha de consulta 21/11/2017].

${ }^{7}$ La interacción con este tipo de libros, en los que en ocasiones se integran elementos sonoros, se produce a través de pegatinas, adhesivos, solapas o lengüetas desplegables, que estimulan la curiosidad e invitan a la cooperación.
} 
animaciones e infografías que compensan la escasa iniciación en la lectoescritura ${ }^{8}$.

Esta propuesta audiovisual, lejos de suponer una amenaza para el desarrollo del hábito de lectura, puede utilizarse, con la mediación adecuada, como instrumento aliado para favorecer la adquisición de competencias como la lectora y la comunicativa. No se deben desdeñar las múltiples posibilidades que ofrecen los libros digitales interactivos, portadores de historias similares a las de la literatura tradicional pero dotados de la carga lúdica y expresiva propias del ámbito multimedia9. Sampaio, Tavares y Silva (2012) destacan la importancia de la figura mediadora como transmisora de estrategias adecuadas para la descodificación e interpretación de los cuentos interactivos digitales. Asimismo, ponen en valor estos productos para la iniciación en la experimentación y expresión estética desde edades tempranas.

\section{Las apps de Realidad Aumentada}

La Realidad Aumentada (RA, o en inglés AR) es una tecnología que utiliza recursos como el GPS o las webcams para superponer imágenes generadas de manera virtual e instantánea en el mundo real, de modo que el usuario o la usuaria percibe una realidad mixta (real y digital) de forma simultánea (Cadeñanes, 2014) ${ }^{10}$. En el campo de la lectura, la RA implica que el contenido sobre papel impreso pueda ser enriquecido o animado, de acuerdo con múltiples posibilidades multimedia que beben de los avances en el campo de la animación y las narrativas digitales ${ }^{11}$.

\footnotetext{
8 Asimismo, los botones e hipervínculos facilitan tres posibilidades de interacción muy atractivas para el alumnado de Educación Infantil: aquella que se produce con la presión de un botón digital, la que surge de forma automática (a modo de película breve que emerge), y la que utiliza efectos especiales como simular el paso de páginas de un libro o accionar mediante animación los desplegables del menú (Navarro, 2015: 264-265).

${ }_{9}$ Los pequeños juegos que se integran en las aplicaciones interactivas y se nutren de imágenes en movimiento son óptimos para el desarrollo de la psicomotricidad fina, al tiempo que contribuyen a activar la sensibilidad estética por medio de imágenes y palabras que pueden contar con un valor artístico.

${ }_{10}$ Se trata de una herramienta interactiva que se está abriendo paso con gran rapidez en ámbitos tan diversos como la arquitectura, la medicina, el arte, la publicidad, la industria de los videojuegos o la educación.

11 Una vez más, se localizan paralelismos con los libros pop-up en papel, en tanto que de ellos surgen de manera sorpresiva figuras tridimensionales. La RA toma estas ideas y las traslada a un plano virtual, caracterizado por la hibridez de géneros.
} 
El alumnado de Educación Infantil encuentra más sencillo e intuitivo interaccionar con las historias de los libros ilustrados cuando los personajes, los espacios y los objetos se despliegan ante sus ojos y cobran vida ${ }^{12}$. El contraste entre la imagen en dos dimensiones, estática, y el efecto al observarla a través de la pantalla resulta sorprendente y divertido, con lo cual se aporta a la experiencia lectora un plus de motivación. Muchas veces, a través del smartphone, tableta u ordenador portátil, pueden visionarse finales alternativos de la historia, giros en el argumento o pautas que facilitan la comprensión del relato, con lo cual se estaría garantizando la vinculación del lector o la lectora con el texto, por medio de recursos lúdicos ${ }^{13}$.

Dicho de otro modo, la RA permite descubrir lo que se esconde en las páginas de los álbumes ilustrados, actividad que resulta altamente motivadora para niños y niñas de corta edad y facilita un aprendizaje por descubrimiento (Navarro, 2015). De esta manera, con solo mirar el libro a través de una pantalla, emergen de sus páginas más aventuras, información sobre los personajes, así como nuevas posibilidades como hacerse una foto con el personaje favorito, dibujarlo, ayudarlo en sus tareas $\mathrm{u}$ ordenar la historia ${ }^{14}$.

De acuerdo con su relación con el libro físico, en términos de Genette, esta herramienta paratextual entraría dentro de la categoría de epitexto, pues se necesita descargar un programa para acceder a sus posibilidades y es imprescindible contar con una pantalla que mediatiza la lectura. Sin embargo, la vinculación con el libro impreso es absoluta, ya que -como se explicaba- la RA se proyecta sobre sus páginas. Se trata de una relación complementaria en la cual el libro sigue manteniendo su protagonismo y la aplicación funciona como apéndice o anexo. En la actualidad muchas editoriales infantiles, como la

\footnotetext{
12 "Las aplicaciones de realidad aumentada ofrecen las imágenes generadas por ordenador y las imágenes bidimensionales dispuestas en falso 3D, mediante la superposición de diversas capas, y aportan a las imágenes una mayor profundidad de campo, si los comparamos con su homónimo, el libro ilustrado" (Navarro, 2015: 268).

13 Para visualizar todas estas sorpresas es necesario contar con conexión a internet, una cámara (que puede estar integrada en una tableta, ordenador o smartphone) y la aplicación específica de RA, a la que se puede acceder a menudo de forma sencilla por medio de un lector de código QR de descarga, a través de la propia cámara del dispositivo.

${ }^{14}$ Sirva como ejemplo el caso del álbum ilustrado Zapatos, zapatitos y zapatones (2015), de Jordi Palet i Puig y Ester Llorens Artiola, de la Editorial Parramón, cuyas posibilidades en RA se muestran en el siguiente vídeo publicitario: https://www.youtube.com/watch?v=PsCwt0OGGXE [Fecha de consulta: 21/11/2017].
} 
citada Parramón, Kókinos o Kalandraka, incorporan en las portadas de sus álbumes ilustrados la información sobre la posibilidad de usar RA, de forma que señalan esta novedad como un complemento atractivo a la lectura tradicional.

En cuanto al potencial educativo de la RA, Cadeñanes (2014: 318) da cuenta de distintos proyectos que exploran con personas adultas o niños y niñas las ventajas de utilizar este recurso, de acuerdo con las teorías educativas de Bloom y Ausube ${ }^{15}$. La posibilidad de combinar el libro ilustrado físico con animación integrada y recursos multimedia, a través de una app,

añade claridad visual y facilita la comprensión de la historia. Además, permite incorporar nuevos elementos que convierten la lectura en un espacio donde el lector tenga la capacidad de intervenir e interactuar con elementos en la escena, generando nuevas lecturas, y, por tanto, nuevas experiencias que le hagan sumergirse en la historia y conectar con los personajes (Navarro, 2015: 265).

En definitiva, la RA ofrece la posibilidad de experimentar la lectura de una manera interactiva y a través de la inmersión, de forma que el componente real y el virtual se dan la mano para invitar al alumnado a dejarse capturar por la historia.

\section{Participantes y objetivos}

En la experiencia de investigación que aquí se propone ha participado alumnado de tercer curso del Grado en Educación Infantil de la Universidad de Córdoba (curso 2017-2018). Se trata de 61 estudiantes que se encargaron de buscar y seleccionar materiales de narrativa digital con los que desarrollar su papel mediador respecto al alumnado de Educación Infantil.

En cuanto a las personas destinatarias, se puede señalar a docentes en Grado en Educación Infantil que pretendan incorporar materiales novedosos a sus clases con la intención de facilitar estrategias para la animación a la lectura. Asimismo, este trabajo puede ser útil para docentes en Educación

\footnotetext{
15 En concreto, Cadeñanes (2014) menciona el proyecto de Dünser y Hornecker, que consiste en el visionado de páginas de libros infantiles en realidad aumentada, usando personajes animados en 3D, sonido y tareas interactivas. Destaca también en el ámbito infantil el estudio de McKenzi y Dernell, basado en indagar acerca de los efectos de un libro en realidad aumentada a través de un visor. Los niños y las niñas disfrutarían de la animación del contenido digital y escuchar el audio (Cadeñanes, 2014: 318).
} 
Infantil, pues recoge recursos y actividades para abordar temáticas en el aula desde las narrativas digitales.

Esta experiencia fue planteada en forma de práctica integrada en la programación curricular del aula. En concreto, está vinculada a la adquisición y desarrollo de las competencias de la materia anual Desarrollo de Habilidades Lingüísticas y sus Didácticas. De acuerdo con ello, se plantean los siguientes objetivos para el alumnado universitario de Grado en Educación Infantil:

1. Utilizar las narrativas digitales como herramienta para promocionar la lectura en el aula de Educación Infantil.

2. Seleccionar booktrailers, libros ilustrados digitales y aplicaciones de RA que sean de calidad óptima para el tratamiento de temáticas concretas en Educación Infantil.

3. Reflexionar desde una perspectiva crítica acerca de los materiales seleccionados, destacando su potencial educativo y adelantándose a los posibles inconvenientes de su uso.

4. Diseñar actividades concretas, vinculadas a las necesidades y particularidades del alumnado de Educación Infantil, basadas en las herramientas digitales antes seleccionadas.

5. Desarrollar la creatividad y los recursos lúdicos para formarse como figuras mediadoras en la formación literaria infantil.

6. Mejorar las habilidades lingüísticas, tanto a nivel oral como escrito.

7. Trabajar de manera cooperativa.

\section{Instrumentos y metodología}

La experiencia de investigación que nos ocupa emplea la práctica docente como principal instrumento para el avance en el conocimiento. Se parte de la investigación en narrativas digitales, por parte del alumnado de grado, como punto de partida para elaborar propuestas didácticas vinculadas a temas de interés para la etapa de Educación Infantil.

Para el desarrollo de la práctica en el aula universitaria, el alumnado se dividió en 12 grupos de trabajo constituidos por 4-6 personas. Cada grupo tuvo que trabajar de forma cooperativa para tomar decisiones y generar una programación didáctica de calidad, basada en las narrativas digitales e idónea para la etapa educativa seleccionada (de 3 a 6 años). Se ha trabajado desde 
un enfoque interactivo y constructivista, según el cual el alumnado universitario actuaba como protagonista de su proceso de aprendizaje. Asimismo, se ha incentivado al uso la creatividad en la búsqueda de actividades motivadoras destinadas a desarrollar la imaginación del alumnado infantil.

De acuerdo con el procedimiento para la selección de materiales digitales, se facilitaron tuvieron en cuenta cuatro directrices que se enumeran a continuación. Si bien existen diferencias notables en las distintas edades (de 3 a 6 años) y en función del nivel individual de desarrollo y de adquisición de la lectoescritura, se puede afirmar de forma general que 1) es importante que en Ios materiales elegidos el componente verbal escrito sea limitado para facilitar su comprensión; 2) han de buscarse recursos sencillos desde un punto de vista narrativo, lo cual se plasma en la necesidad de que la construcción de personajes y espacios sea simple, tanto desde el punto de vista cuantitativo como cualitativo; 3) el uso de la música, la animación y elementos visuales como los colores llamativos son recursos acertados para captar la atención y conseguir un efecto de inmersión en la historia; 4) por último, resulta crucial seleccionar temáticas afines a la etapa, basadas en aspectos muy cercanos a la subjetividad del alumnado de Educación Infantil, que fomenten su desarrollo cognitivo y una relación empática con su entorno más próximo.

\section{Resultados y evaluación}

La práctica realizada, que ocupó cuatro sesiones de clase (de hora y media cada una ${ }^{16}$ ), ha potenciado el papel mediador de los futuros educadores y educadoras con respecto a la literatura infantil. Cada grupo eligió libremente una temática concreta relacionada con Educación Infantil y tres productos digitales (un booktrailer, un cuento interactivo digital y una aplicación de RA) adecuados a la etapa y ciclo de Educación Infantil, de acuerdo con las directrices aportadas previamente. En la última sesión tenían que proponer un modo adecuado de llevar los tres materiales digitales al aula, acompañados de dinámicas de 30 minutos en las que se trabajase el tema elegido en el aula de Educación Infantil.

\footnotetext{
${ }^{16}$ Excepto la última sesión, en la que el grupo se dividió en dos mitades, asistiendo cada una a hora y media de exposiciones. La experiencia duró un total de siete horas y media para la docente y seis horas para el alumnado.
} 
Se exponen a continuación los 23 productos de narrativa digital que fueron expuestos por el alumnado, divididos en temáticas de gran relevancia para educación infantil como la educación emocional, la colaboración entre las personas, la diversidad familiar y el mundo animal. Las herramientas digitales se pueden dividir en 8 booktrailers, 9 cuentos digitales interactivos y 6 aplicaciones de RA para cuentos ${ }^{17}$. A continuación, se explicitarán dichos materiales, acompañados de una breve reflexión sobre las estrategias didácticas más relevantes que han surgido en las exposiciones.

\section{Educación emocional}

Booktrailer:

- Paula y su cabello multicolor (dos grupos seleccionaron este material) https://www.youtube.com/watch?v=K4Zk7p7FNOk [fecha de consulta: 21/11/2017]

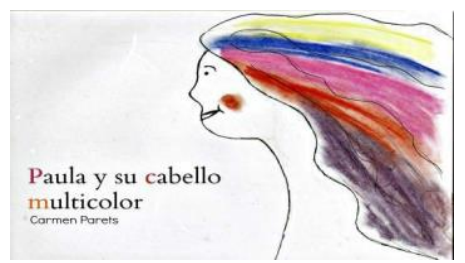

Fig. 1. Paula y su cabello multicolor, portada

- Dos booktrailers de El monstruo de los colores https://www.youtube.com/watch?v=_NmMOkND8g (dos grupos seleccionaron este material) https://www.youtube.com/watch?v=ehROLI9LSIE [fecha de consulta: 21/11/2017]

Cuento interactivo digital:

- El monstruo de los colores http://www.editorialflamboyant.com/el-monstruo-de-colores-app/ [fecha de consulta: 21/11/2017]

- Del revés https://www.youtube.com/watch?v=vClqgtGlHoo. [fecha de consulta: 21/11/2017]

- Cuerdas (dos grupos seleccionaron este material) http://www.suiteson.com/ [fecha de consulta: 21/11/2017]

17 Como se detallará a continuación, hubo varios materiales repetidos por distintos grupos, debido a su clara adecuación a la temática, a su atractivo o, en algunos casos, a la publicidad. Este último factor se detecta de manera especial en productos relacionados con el tema de las emociones, muy de moda en la actualidad. 
- ¿Qué hacemos con el enfado? https://www.youtube.com/watch?v=qM3BHQR3Ek [fecha de consulta: 21/11/2017]

\section{Apps de RA:}

- El erizo que no se quería pinchar (Ester Alsina, Parramón, 2017). Este álbum forma parte de la colección "Cuentos para emocionarse" (tres grupos seleccionaron este material). https://www.boolino.es/es/libros-cuentos/el-erizoque-no-se-queria-pinchar/ [fecha de consulta: 21/11/2017]

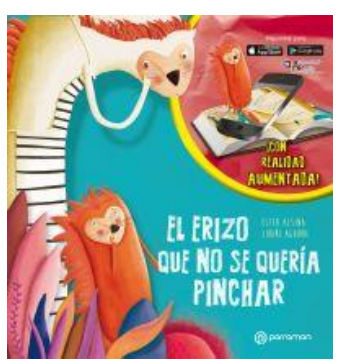

Fig. 2. El erizo que no se quería pinchar, portada

- Medusa se ha vuelto a enfadar (Ester Alsina, Parramón, 2017), también de la colección "Cuentos para emocionarse" (tres grupos seleccionaron este material).

https://www.youtube.com/watch?v=e7NMqnFtWNo (vídeo promocional) https://www.boolinobookbox.es/tienda/detalle/medusa-se-ha-vuelto-enfadar/ (enlace al recurso) [fecha de consulta: 21/11/2017]

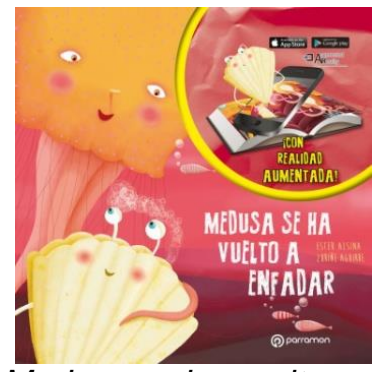

Fig. 3. Medusa se ha vuelto a enfadar, portada

Las actividades que acompañaban a dichos materiales se basaron en su mayoría en el trabajo con la expresión de las emociones y la empatía. Se propusieron asambleas tras el visionado del booktrailer, seguidas de lluvias de ideas en las que se incorporaban preguntas sobre las propias emociones del alumnado. Resultó muy recurrente el recurso de detener el vídeo para 
interaccionar con los niños y las niñas, de acuerdo con estrategias de anticipación (¿Qué crees que va a suceder ahora?) ${ }^{18}$.

Para la presentación de los libros interactivos digitales en el aula de Educación Infantil, se plantearon comentarios previos en los que se explicaría que existen muchas maneras de leer un cuento. Se vincularía, de este modo, la tradicional lectura en papel con otras en tableta, ordenador o pizarra digital. Estos materiales dieron lugar a juegos, así como a preguntas al alumnado infantil acerca de las acciones que desarrollaban los personajes. Otras de las actividades interactivas fueron ordenar las emociones del cuento (en la app de El monstruo de los colores), escuchar o leer la historia o interaccionar con los personajes con dinámicas que planteaba la propia aplicación. Estas herramientas digitales proponen estrategias para reconocer y gestionar emociones como el enfado a través de actividades sencillas.

Por su parte, los materiales de RA seleccionados ofrecían a la lectura en papel nuevas posibilidades como jugar, dibujar o contemplar el despliegue de personajes en 3D.

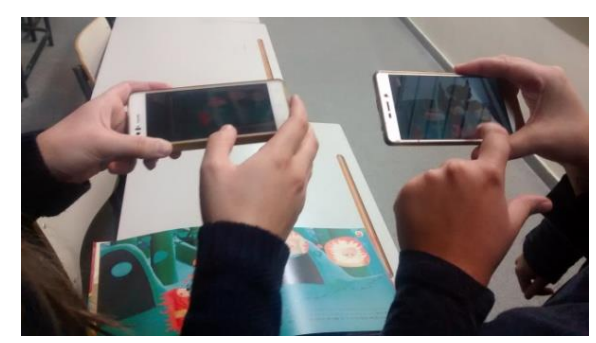

Fig. 4. Imagen tomada de la práctica en el aula

En las dinámicas propuestas se completaron las actividades que incluía la tecnología con otras más tradicionales en las que se dejaba a un lado la pantalla para que el alumnado elaborase materiales propios a partir de las ideas del cuento. Dibujar en papel o cartulina las emociones o realizar en plastilina figuras de los personajes fueron algunas de las ideas que surgieron.

\footnotetext{
${ }^{18}$ Asimismo, para el caso de El monstruo de los colores, en uno de los grupos se propuso a cada niño o niña dibujar su propio monstruo de las emociones.
} 
Dos grupos plantearon la participación de las familias en el aula para facilitar la experimentación con la $\mathrm{RA}^{19}$.

Al hilo de los tres tipos de material digital, surgieron actividades que implicaban el uso de objetos simbólicos para visualizar y manejar las emociones ${ }^{20}$. Estos elementos sirven para que los niños y las niñas fijen la atención en momentos de tensión, distingan la emoción que sienten y se relajen ${ }^{21}$. Por último, otra estrategia muy destacable fue la utilización de láminas de animales para representar los distintos tipos de enfado (tortuga, león o búho) ${ }^{22}$.

\section{Relaciones interpersonales: la familia y la amistad ${ }^{23}$}

\section{Booktrailer:}

- Mi familia es de otro mundo (dos grupos seleccionaron este material) https://www.youtube.com/watch?v=U4Au6iEJgl4 [fecha de consulta: 21/11/2017]

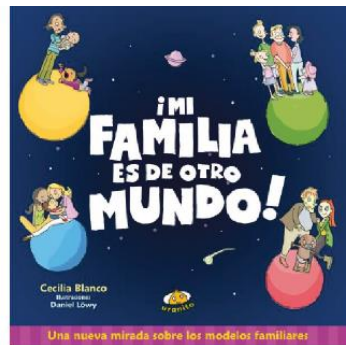

Fig. 5. Mi familia es de otro mundo, portada

- Mi abuela no es la de antes (dos grupos seleccionaron este material) https://www.youtube.com/watch?v=ee-FsQgmVKk

[fecha de consulta: 23/11/2017]

${ }^{19}$ Se conformarían equipos por colores y en cada uno la persona adulta portaría una tableta para mostrar de forma ordenada al alumnado las sorpresas y retos que iban surgiendo de las páginas.

20 Se propuso la elaboración de botes de las emociones (con un color para cada emoción), frascos de la calma (donde se metería el dibujo de la emoción negativa para que desaparezca) o botellas de la calma (llenas de purpurina).

${ }^{21}$ Con este propósito de hacer visible lo complejo, no faltó un grupo que diseñó una "ruleta de las emociones" y otro que utilizó ovillos de lana de distintos colores para diferenciar los estados de ánimo, de acuerdo con la historia de El monstruo de los colores.

22 Este juego procede del portal de Educación Infantil y Primaria Educapeques: https://www.educapeques.com/recursos-para-el-aula/juegos-para-ninos/juego-educativoenfado.html [fecha de consulta: 21/11/2017]

${ }^{23}$ Este conjunto de actividades se centró en dar visibilidad a los diversos tipos de familia (nuclear, monoparental, extensa, adoptiva, homoparental, etc.), así como destacar el valor de las relaciones inter-generacionales o entre iguales. 
- La misión de las ovejas guerreras.

https://www.youtube.com/watch?v=adVR63Dz4Vk [fecha de consulta: 23/11/2017]

Cuento interactivo digital:

- Pelayo y su pandilla (dos grupos seleccionaron este material) http://nea.educastur.princast.es/repositorio/RECURSO_ZIP/1_ibcmass_u10_m edio/index.html [fecha de consulta: 23/11/2017]

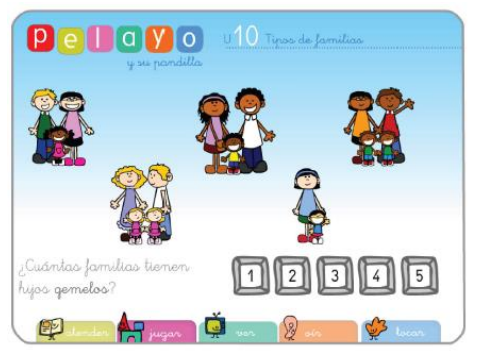

Fig. 6. Captura de pantalla de la app Pelayo y su pandilla

- Me: a Kid's Diary https://tinybop.com/apps/me [fecha de consulta: 23/11/2017]

- Un deseo por Navidad https://youtu.be/oK50mTn_epM (enlace de demostración en Youtube) http://www.frikids.com/un-deseo-por-navidad/ [fecha de consulta: 23/11/2017]

- Blancanieves

https:/itunes.apple.com/es/app/blancanieves-cuentos-cl\%C3\%A1 sicosinfantiles-premium/id1121137539?mt=8 [fecha de consulta: 23/11/2017]

Apps de RA:

- El árbol de Navidad (BooksARalive, 2015) http://www.educadiver.es/el-arbolde-navidad-la-navidad-vive-en-un-libro-2/ (dos grupos seleccionaron este material) [fecha de consulta: 23/11/2017]

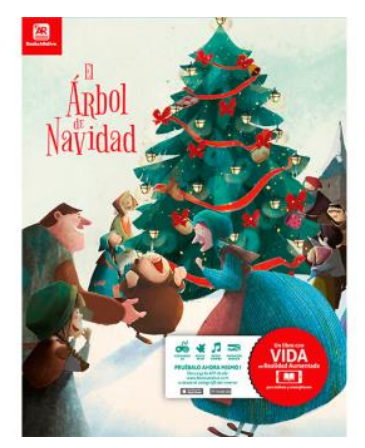

Fig. 7. El árbol de Navidad, portada 
- Ice Age. La formación de los continentes (Larouse, 2012)

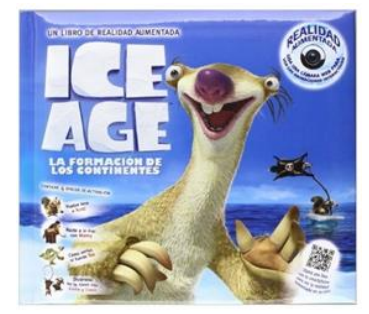

Fig. 8. Ice Age, portada

Una vez más, surgieron asambleas previas a las actividades en las que se preguntaría al alumnado qué entienden por familia o cómo es la suya. Como recurso innovador, se ha incorporado el humor en la selección del divertido booktrailer La misión de las ovejas guerreras, seguido de la pregunta "¿Qué misión creéis que tienen que conseguir las ovejas?". Las respuestas se darían a través de un Kahoot, que recogería tres posibilidades acerca de lo que les podría suceder.

Los materiales digitales dieron lugar a actividades como la creación de un álbum familiar de la clase o árboles genealógicos (en cartulina o con la app Me: a Kid's Diary). Las dinámicas más destacables fueron la identificación y reconocimiento de distintas modalidades de familias con viñetas y aquellas que pedían al alumnado que contase o dibujase actividades que realizaban en familia. Las aplicaciones con cuentos interactivos que se mostraron en las exposiciones incorporaban juegos para ver, oír y tocar (con audios, puzles y actividades para colorear en la tableta) y ofrecían en algunos casos la posibilidad de descargar plantillas para colorear en papel escenas 0 personajes.

En cuanto a la RA, a partir del cuento Un deseo por Navidad, las mediadoras elaboraron la actividad "Mi deseo por Navidad", en la que cada niño o niña tendría que escribir una carta a Papá Noel pidiendo algo para un familiar. Surgió también la idea de atribuir al "niño o niña protagonista" la tarea de mostrar al grupo la RA, portando la tableta con la ayuda del educador o la educadora. El resto de la clase tendría que hacer un dibujo al finalizar la lectura, con el cual se recogería su interpretación del álbum. 


\section{El mundo animal ${ }^{24}$}

Booktrailers:

- Dragones en el cielo (se parte de un ser fantástico para a continuación relacionarlo con animales reales en las actividades)

https://www.youtube.com/watch?v=9CWQ8YErs3s [Fecha de consulta: 21/ 11/2017]

- A qué sabe la luna https://www.youtube.com/watch?v=b9DVM8LKCt4. [Fecha de consulta: 21/ 11/2017]

Cuento interactivo digital:

- Un día en la granja (dos grupos seleccionaron este material), que se puede visualizar en el siguiente vídeo de Youtube https://www.youtube.com/watch?v=nJt_rf690ag [Fecha de consulta: 21/ 11/2017].

Apps de RA:

- Conoce los animales. La granja (BooksARalive, 2015), que puede verse en la siguiente demostración https://www.youtube.com/watch?v=VujuW5ThQV8 [Fecha de consulta: 21/ 11/2017] (dos grupos seleccionaron este material).

- La liebre y la tortuga, app de RA que funciona con plantillas de la fábula tradicional que se imprimen y colorean (en este caso, sin la presencia de un libro concreto).

http://www.elisayuste.com/lectura-recomendada-la-liebre-y-la-tortuga/ [fecha de consulta: 21/11/2017]

A través de estas herramientas surgieron asambleas, preguntas directas referidas a las mascotas reales de los niños y las niñas, actividades motoras basadas en las distintas historias y otras que incidían en el desarrollo de la psicomotricidad fina: colorear plantillas de animales que a continuación tomaban vida con la RA, identificar sus nombres, tamaños y crías o elaborar animales con distintos materiales. Dada la relevancia de la temática en Educación Infantil, se propusieron también experiencias de contacto directo con animales, en el aula o a través de excursiones.

\footnotetext{
24 Las actividades realizadas en este ámbito fueron encaminadas a potenciar en el alumnado infantil la responsabilidad de los cuidados y el respeto a todos los seres vivos.
} 
El sistema de evaluación de esta práctica fue continuo y formativo, de modo que se promovió la reflexión acerca del proceso a lo largo de sus fases, tanto por parte de la docente como del alumnado. Asimismo, en la cuarta sesión la docente realizó una evaluación final cualitativa, de acuerdo con tres niveles de desempeño 25 .

\begin{tabular}{|l|l|l|l|}
\hline Valoración del trabajo & 1 & 2 & 3 \\
\hline $\begin{array}{l}\text { Las actividades propuestas establecen un vínculo entre los materiales } \\
\text { digitales y las necesidades y realidades del alumnado de E. Infantil. }\end{array}$ & & & \\
\hline $\begin{array}{l}\text { Se justifica de manera suficiente la selección de dichos materiales } \\
\text { digitales de acuerdo con las temáticas abordadas. }\end{array}$ & & \\
\hline $\begin{array}{l}\text { Los recursos digitales seleccionados resultan adecuados para la edad } \\
\text { del alumnado seleccionada. }\end{array}$ & & \\
\hline $\begin{array}{l}\text { Los recursos digitales seleccionados hacen un ustístico e } \\
\text { imaginativo de la palabra. }\end{array}$ & & \\
\hline $\begin{array}{l}\text { Los recursos digitales seleccionados cuentan con una calidad estética } \\
\text { suficiente en los gráficos e ilustraciones para ser utilizados en el aula de } \\
\text { E. Infantil. }\end{array}$ & & & \\
\hline $\begin{array}{l}\text { Las actividades para Educación Infantil resultan lúdicas, amenas y } \\
\text { divertidas. }\end{array}$ & & & \\
\hline $\begin{array}{l}\text { Se le pide al alumnado que aporte en forma oral, dibujada, } \\
\text { representada, etc. sus impresiones acerca de la experiencia digital. }\end{array}$ & & \\
\hline
\end{tabular}

\begin{tabular}{|l|l|l|l|}
\hline Valoración de la presentación oral & 1 & 2 & 3 \\
\hline $\begin{array}{l}\text { Utiliza la voz de manera clara y significativa: realiza pausas, el volumen } \\
\text { y la velocidad son adecuados en la exposición. }\end{array}$ & & \\
\hline $\begin{array}{l}\text { Utiliza los gestos de forma significativa y clara. El lenguaje no verbal } \\
\text { acompaña y refleja el sentido de lo expuesto: gestos, posturas y } \\
\text { movimiento en el espacio. }\end{array}$ & & & \\
\hline $\begin{array}{l}\text { Existe contacto visual con el público y se entabla con él una relación de } \\
\text { empatía a lo largo de las exposiciones. }\end{array}$ & & \\
\hline $\begin{array}{l}\text { Transmite las directrices sobre las actividades de forma clara y sencilla. } \\
\text { Se tiene en cuenta la función mediadora entre el texto/imagen y el } \\
\text { público infantil. }\end{array}$ & & & \\
\hline
\end{tabular}

Fig. 9. Tablas de elaboración propia

${ }^{25}$ Se utilizó una escala de 1 a 3 , en la que 1 significaba no conseguido o en proceso; 2 , conseguido, y 3 , excelente. El conocimiento de los ítems que serían utilizados para la evaluación final sirvió de pauta u orientación para el alumnado a lo largo del proceso. 
En cuanto a la calificación final de la práctica, el nivel de los trabajos fue muy alto $^{26}$. Para completar la evaluación, el alumnado respondió a un cuestionario individual semiestructurado en el que se pedía reflexionar acerca de los aspectos que consideraban más acertados y las dificultades a las que se habían enfrentado a lo largo de las cuatro sesiones ${ }^{27}$.

\section{Conclusiones}

La investigación experimental aquí descrita busca desarrollar las estrategias didácticas necesarias para introducir las narrativas digitales en el aula de Educación Infantil. Se ha hecho hincapié en la necesidad de presentar los materiales audiovisuales acompañados de dinámicas y reflexiones que potencien su valor educativo. En este sentido, es imprescindible hacer un uso responsable de las tecnologías, de forma que la figura docente tenga presentes ciertas desventajas que podrían derivarse de un abuso del medio digital en edades tan tempranas. Por ello, resulta imprescindible utilizar un enfoque comunicativo y dosificar este tipo de experiencias, que en ningún momento deben sustituir la interacción con textos e ilustraciones en papel o los relatos narrados en vivo. En este sentido, parece una buena directriz combinar las experiencias en pantalla con actividades posteriores basadas en la expresión lingüística, la manipulación de materiales físicos y las relaciones interpersonales. De este modo, las experiencias multimedia, en lugar de aislar al alumnado de su entorno, servirán como complemento o estímulo para su óptimo desarrollo socioafectivo.

Las actividades aquí recogidas facilitan el tratamiento de temáticas concretas esenciales para Educación Infantil, así como el acercamiento a la narrativa, a través de las estrategias utilizadas por los nuevos productos digitales. Los 23 materiales seleccionados se basan en relatar una historia, protagonizada por unos personajes con los que el alumnado infantil está

\footnotetext{
${ }^{26}$ Dos grupos obtuvieron la máxima calificación (3 puntos); cuatro grupos, 2,9; cuatro grupos, entre 2,6 y 2,8, mientras que solo un grupo contó con una puntuación de 2,3.

${ }^{27}$ En cuanto a elementos positivos, se consideró la experiencia dinámica, motivadora, actual e informativa. También se puso en valor la posibilidad de investigar sobre recursos tecnológicos, atractivos para trabajar la lectura en Educación Infantil. De acuerdo con los aspectos mejorables, se puso de manifiesto que la libre elección de temáticas produjo ciertas repeticiones evitables.
} 
llamado a identificarse, de una manera novedosa. Se trata, en definitiva, de poner a los niños y las niñas en interacción con relatos y aventuras que resultan idóneos para que desarrollen la imaginación y la empatía, despierten su curiosidad lectora y se familiaricen con el uso estético de la imagen y la palabra. Las narrativas digitales ofrecen al alumnado poco iniciado en la lectoescritura experiencias de lectura acordes con sus necesidades y generan una familiaridad con los cuentos idónea para la formación del hábito lector.

En estos primeros años, en los que existe una curiosidad natural por la exploración y el aprendizaje, la literatura, los recursos tecnológicos y la creatividad deben darse la mano en el aula de Educación Infantil para cristalizar, con la mediación adecuada, en forma de experiencias y actividades lúdicas que contribuyan al desarrollo y a la socialización.

\section{Bibliografía}

CAdeÑANES GaRNICA, Jorge Jonathan (2014). Realidad aumentada en libros digitales educativos y juegos interactivos, tesis doctoral de la Universidad de Salamanca, en Repositorio Gredos de la Universidad de Salamanca. https://gredos.usal.es/jspui/handle/10366/125274 [Fecha de consulta: 21/11/2017].

CASSANY, Daniel (2011). "Después de internet...". Textos, 57, pp. 12-22.

CASSANY, Daniel (2012). En-línea. Leer y escribir en la red. Barcelona: Anagrama.

GENETTE, Gérad (1987). Seuils. Paris: Éditions du Seuil.

GRAY, Jonathan (2010). Show sold separately. Promos, spoilers, and other media paratexts. New York and London: New York University Press.

IBARRA-RIUS, Noelia; BALLESTER-RocA, Josep (2016). "Booktrailer en Educación Infantil y Primaria: adquisición y desarrollo de las competencias comunicativa, digital y literaria a través de narrativas digitales", Digital Education Review, 30, pp. 76-93. https://dialnet.unirioja.es/descarga/articulo/5772443.pdf [Fecha de consulta: 21/11/2017].

Lloret Romero, Nuria; Canet Centellas, Fernando (2008). "Nuevos escenarios, nuevas formas de expresión narrativa: La Web 2.0 y el lenguaje audiovisual". Hipertext.net. Revista Académica sobre Documentación Digital y comunicación Interactiva, 6, pp. 1-11. https://www.upf.edu/hipertextnet/numero-6/lenguaje-audiovisual.html [Fecha de consulta: 21/11/2017].

LANDOW, George P. (2009). Hipertexto 3.0.Teoría crítica y nuevos medios en la era de la globalización. Barcelona: Paidós. 
Lluch, Gemma; Tabernero-Sala, Rosa y Calvo-Valios, Virginia (2015). "Epitextos virtuales públicos como herramientas para la difusión del libro", El profesional de la información, 24, 6, pp. 797-804.

MENDOZA FILLOLA (2003). "El proceso de lectura. Las estrategias", en Pedro C. CERRILlO y Santiago YUBERO (eds.), La formación de mediadores para la promoción de la lectura, pp. 183-199.

MENDOZA FILLOLA (2007). "El proceso lector. Proceso y metacognición". En Pedro C. CerRillo, Cristina Cañamares y César SÁnChez OrTIZ (eds.), Literatura infantil: nuevas lecturas, nuevos lectores. Cuenca, Ediciones de la Universidad de Castilla-La Mancha, pp. 69-82.

NAvarRo, Adriana (2015). "La animación en las ilustraciones infantiles del cuento digital interactivo. Del cortometraje al libro ilustrado". En Ilustrafic. Actas del II Congreso Internacional de Ilustración, Arte y Cultura Visual, celebrado en Valencia (1-3 octubre de 2015), pp. 263-269. DOI: http://dx.doi.org/10.4995/ILUSTRAFIC/ILUSTRAFIC2015/377

PALet I PUIG, Jordi; Llorens ARTIOLA, Ester (2005). Zapatos, zapatitos y zapatones. Badalona: Editorial Parramón.

ROVIRA-COLLADO, José (2015). "Redes sociales de lectura: del libro de caras a la LIJ 2.0". Investigaciones Sobre Lectura ISL, 3, pp. 106-122, en http://comprensionlectora.es/revistaisl/index.php/revistalSL/issue/view/7 [Fecha de consulta: 21/11/2017].

ROVIRA-COLLADO, José (2017). Booktrailer y Booktuber como herramientas LIJ 2.0 para el desarrollo del hábito lector, Investigaciones sobre lectura, 7 , 55-72.

Sampalo, Mariana; TAvares, Paula y Silva, Catarina (2012). $A$ experiência do livro ilustrado interativo para a infância. Portugal: Confia. https://www.academia.edu/3993390/A_EXPERI\%C3\%8ANCIA_DO_LIV RO_ILUSTRADO_INTERATIVO_PARA_A_INF\%C3\%82NCIA [Fecha de consulta: 21/11/2017].

SÁNCHEZ-ClAROS, Juan Patricio (2016). "Nuevas alfabetizaciones en un entorno multimodal: nuevas necesidades lectoras para un entorno textual múltiple". Investigaciones sobre Lectura, 6, pp. 51-57. http://comprensionlectora.es/revistaisl/index.php/revistalSL/article/view/1 53/61 [Fecha de consulta: 21/11/2017].

TABERNERO-SALA, Rosa (2013). "El book trailer en la promoción del relato". Quaderns de Filologia. Estudis literaris, 18, pp. 211-222. https://ojs.uv.es/index.php/qdfed/article/download/3302/2973 [Fecha de consulta: 21/11/2017]

TABERNERO-SALA, Rosa (2015). "El book-trailer en la promoción del libro infantil y juvenil". En Rafael JIMÉNEZ-FERNÁNDEZ y Manuel FRANCISCO ROMEROOLIVA (eds.), Nuevas líneas de investigación e innovación en la educación literaria. Barcelona: Octaedro, pp. 99-108.

UnswORTH, Len (2006). E-Literature for Children. Enhancing Digital Literacy Learning. New York: Routledge.

Fecha de recepción: 27 de noviembre de 2017

Fecha de aceptación: 9 de febrero de 2018 